\title{
ORGANIZAÇÃO DO SERVIÇO DE ENFERMĀGEM DE SĀÚDE PÚBLICA DO DEPARTAMENTO AUTÔNOMO DE SÁUDE PÚBLICA DA SECRETARIA DE ESTADO DA SAÚDE DE SANTA CATARINA
}

\author{
M. ${ }^{\text {a }}$ Marlene B. Medeiros ** \\ Ingrid E1sen *
}

\section{I - INTRODUÇÃO}

O presente trabalho visa:

- apresentar a metodologia utilizada na organização do Serviço de Enfermagem de Saúde Pública do Departamento Autônomo de Saúde Pública de Santa Catarina;

- identificar as variáveis que interferiram nas diferentes fases da implantação do Sistema;

- fornecer subsídios aos enfermeiros que desenvolvem atividades de planejamento e implantação de serviços de enfermagem.

\section{2 - HISTÓRICO}

A situação da enfermagem de Saúde Pública até 1970 foi relatada no trabalho "O Papel do Enfermeiro nos Serviços de Saúde em Santa Catarina", apresentado no XXIII Congresso Brasileiro de Enfermagem, em Manaus, em 1971, salientando os seguintes dados:

- coeficiente de mortalidade geral de 5,0 por 1.000 habitantes;

- coeficiente de mortalidade infantil 58 por 1.000 nascidos vivos;

- recursos materiais: 12 Centros de Saúde e 109 Postos de Saúde;

- recursos humanos: 0 (zero) Enfermeiros e 34 (trinta e quatro) visitadoras sanitárias.

\footnotetext{
* - Diretora da Divisão Hospitalar da Secretaria de Estado da Saúde.

* - Chefe da Seção de Enfermagem de Saúde Pública do Departamento Autônomo de Saúde Pública de Santa Catarina.
} 
Em 1971, visando a modernização da estrutura administrativa verificou-se a reorganização da Secretaria de Estado da Saúde, através do Decreto n. ${ }^{\circ}$ SES-24-3-71/08, quando foram criados os órgãos de Assessoria e um órgão de Coordenação de Saúde Pública e Hospitalar.

A Seção de Enfermagem de Saúde Pública, subordinada à Divisão Técnica do Departamento Autôncmo de Saúde Pública (DASP), foi criada de acordo com o artigo 23 do Decreto SES-24-03-71/10, que aprovou o seu regulamento.

De acordo com este decreto é competência do Serviço de Enfermagem:

a - promover estudos, visando identificar problemas de enfermagem de Saúde Pública;

b - ordenar, planejar, executar e avaliar as normas e padrões de enfermagem de Saúde Pública, assegurando integral cumprimento das suas finalidades;

c - promover cursos, estágios e conferências, visando o melhor treinamento e adaptação funcional do pessoal técnico e auxiliar em enfermagem de Saúde Pública e supervisionar os programas de Enfermagem em todas as Unidades Sanitárias;

d - promover e executar as medidas necessárias à Educação Sanitária da população.

e - organizar, manter e operar a filmoteca e biblioteca de assuntos ligados à educação sanitária e o auditório, para uso da população, prioritariamente a que representa a área materno infantil.

Apesar da existência oficial da Seção de Enfermagem de Saúde Pública no DASP, a mesma era inoperante uma vez que o cargo não era preenchido.

Comprovada a necessidade de se preparar enfermeiros para atuarem no Campo de Saúde Pública, o Departamento de Enfermagem da Universidade Federal de Santa Catarina definiu como prioritária a habilitação dos enfermeiros em Saúde Pública. Com este objetivo, a SES (Secretaria de Estado da Saúde) e o Departamento de Enfermagem da UFSC, por convênio, planejaram a organização de um curso para este fim que foi criado pela Portaria n. ${ }^{\circ}$ 19/72 de 14/01/72 e recebeu assessoria da OPS/OMS no que se refere ao planejamento das atividades práticas.

O curso teve início em março de 1972, graduando, em dezembro do mesmo ano, 12 enfermeiros de Saúde Pública.

\section{3 - ETAPAS DA ORGANIZAÇÃO DO SISTEMA DE ENFERMAGEM DE SAÚDE PÚBLICA}

A organização do Serviço de Enfermagem de Saúde Pública do DASP teve seu início em julho de 1972 com a contratação da pri- 
meira enfermeira que também ocupava o cargo de Assessor de Saúde Pública, na Secretaria de Estado da Saúde.

\section{1. - Levantamento dos Recursos Humanos de Enfermagem de Saúde Pública.}

Objetivando o conhecimento da situação da Enfermagem de Saúde Pública, foi feito um levantamento dos Recursos Humanos de Enfermagem em 1970 e 1972, junto à Seção de Pessoal do DASP e ao Núcleo de Recursos Humanos da SES, que acabara de realizar o primeiro Censo neste terreno.

A equipe de Enfermagem era composta dos seguintes elementos: auxiliar de enfermagem, atendentes, visitadora sanitária, parteira e auxiliar de serviços médicos.

A tabela I apresenta a distribuição dos Recursos Humanos de enfermagem de Saúde Pública, segundo nível, distrito sanitário e ano, no DASP.

O nivel Pessoal Auxiliar de Enfermagem agrupou as seguintes categorias: atendentes, visitadoras sanitárias, auxiliar de serviços médicos e parteiras.

Pode-se constatar na referida tabela a inexistência de enfermeira a nível de Distrito Sanitário nos dois anos relacionados no levantamento, o número reduzido de auxiliares de enfermagem e a maior quantificação de pessoal auxiliar de enfermagem.

A tabela II apresenta a distribuição da relação dos Recursos Humanos em enfermagem de Saúde Pública por 10.000 habitantes, segundo Distrito Sanitário no DASP, nos anos de 1970 e 1972, onde podemos constatar a deficiência quantitativa de recursos humanos existentes para prestar atenção de enfermagem à população do Estado.

Igualmente fica evidenciada nesta tabela a deficiência de enfermeiras de Saúde Pública a nível de execução em todos os Distritos Sanitários.

Comparando os resultados apresentados nesta tabela com os padrões estabelecidos pela OPS/OMS para Recursos Humanos de Enfermagem de Saúde Pública, concluiu-se que além da deficiência existente, devem ser estabelecidos padrões condizentes com a realidade catarinense.

Estes resultados demonstram a necessidade de se fazer um estudo mais profundo sobre os Recursos Humanos de Enfermagem do DASP. 


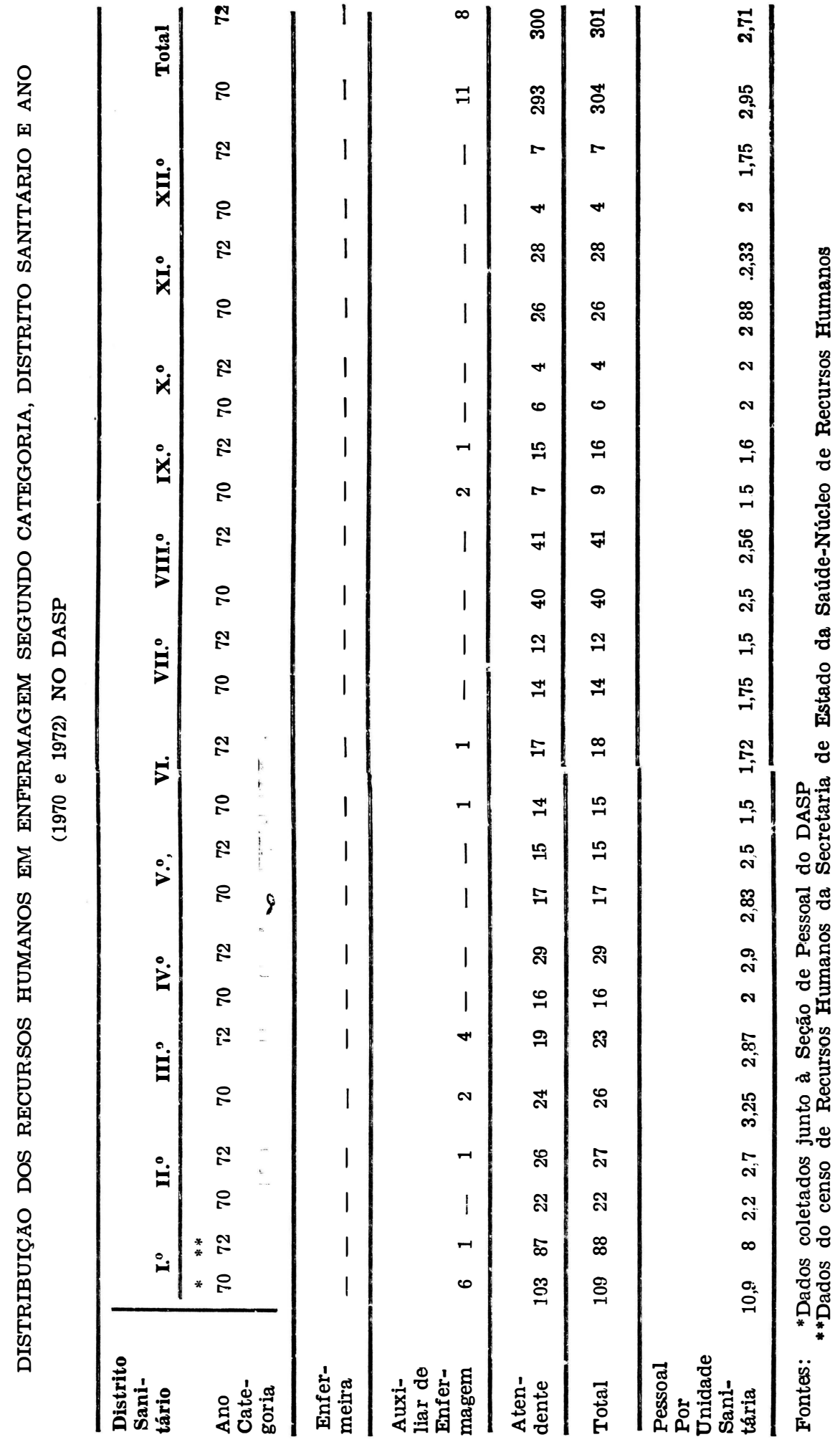




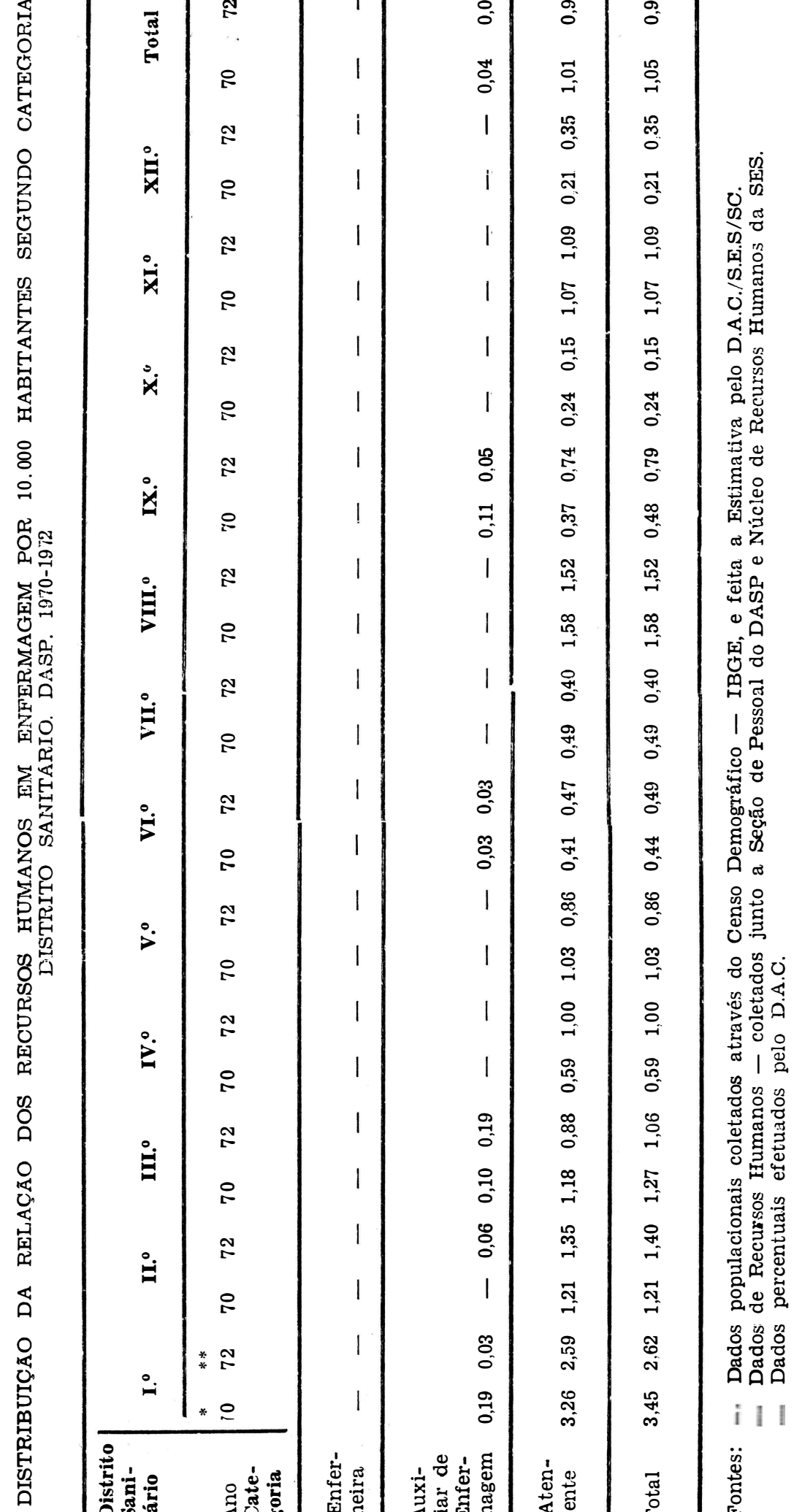


3.2. - Pesquisa para conhecimento da real utilização do pessoal de enfermagem no DASP da Secretaria de Saúde Pública do Estado de Santa Catarina

Visando proporcionar informações sobre a atual utilização dos diferentes níveis do pessoal de enfermagem, foi realizada em 1972, como atividade do curso de Habilitação em Enfermagem de Saúde Pública da UFSC, uma pesquisa que contou com a participação da Seção de Enfermagem do DASP e assessoria da OPS/OMS.

Como universo foi eleito por amostragem intencional o I. ${ }^{\circ}$ DisDistrito Sanitário no qual se realizavam todas as atividades previstas para as Unidades Sanitárias e onde se encontravam todas as categorias de pessoal de enfermagem. Foi considerado na pesquisa como população todos os indivíduos do Serviço de Enfermagem que possuissem preparo específico ou não, inclusive os que apresentavam desvio de função.

$\mathrm{Na}$ população eleita os visitadores sanitários perfaziam um total de $26,8 \%$; os auxiliares de enfermagem, $5,2 \%$; os auxiliares de serviços médicos, $18 \%$, e os atendentes, $50 \%$.

A tabela III apresenta as atividades executadas pelo pessoal do 1. Distrito Sanitário, segundo as categorias e as atividades do pessoal de enfermagem.

As atividades realizadas pelo pessoal de enfermagem nas unidades sanitárias do referido Distrito Sanitário foram classificadas segundo o grau de habilidade.

\section{3. - Definição do Sistema}

Conhecidas as atividades desempenhadas pelo pessoal de enfermagem junto à comunidade, identificadas as limitações referentes à quantificação e qualificação dos recursos humanos, definiu-se o Serviço de Enfermagem do DASP.

As inúmeras fontes bibliográficas consultadas não condiziam com a problemática catarinense, não dando grandes subsídios para a. organização do Serviço, daí concluiu-se que o mesmo deveria ser estruturado dentro de um novo enfoque. Foi escolhida a abordagem sistêmica uma vez que era-se de opinião que oferecia melhores condições para o desenvolvimento da enfermagem de Saúde Pública.

Desejava-se um serviço dinâmico, coeso, coordenado com os demais setores do DASP, com os órgãos formadores de recursos humanos e instituições de Saŭde, constantemente se auto avaliando e procurando melhorar o padrão de atendimento à comunidade. 


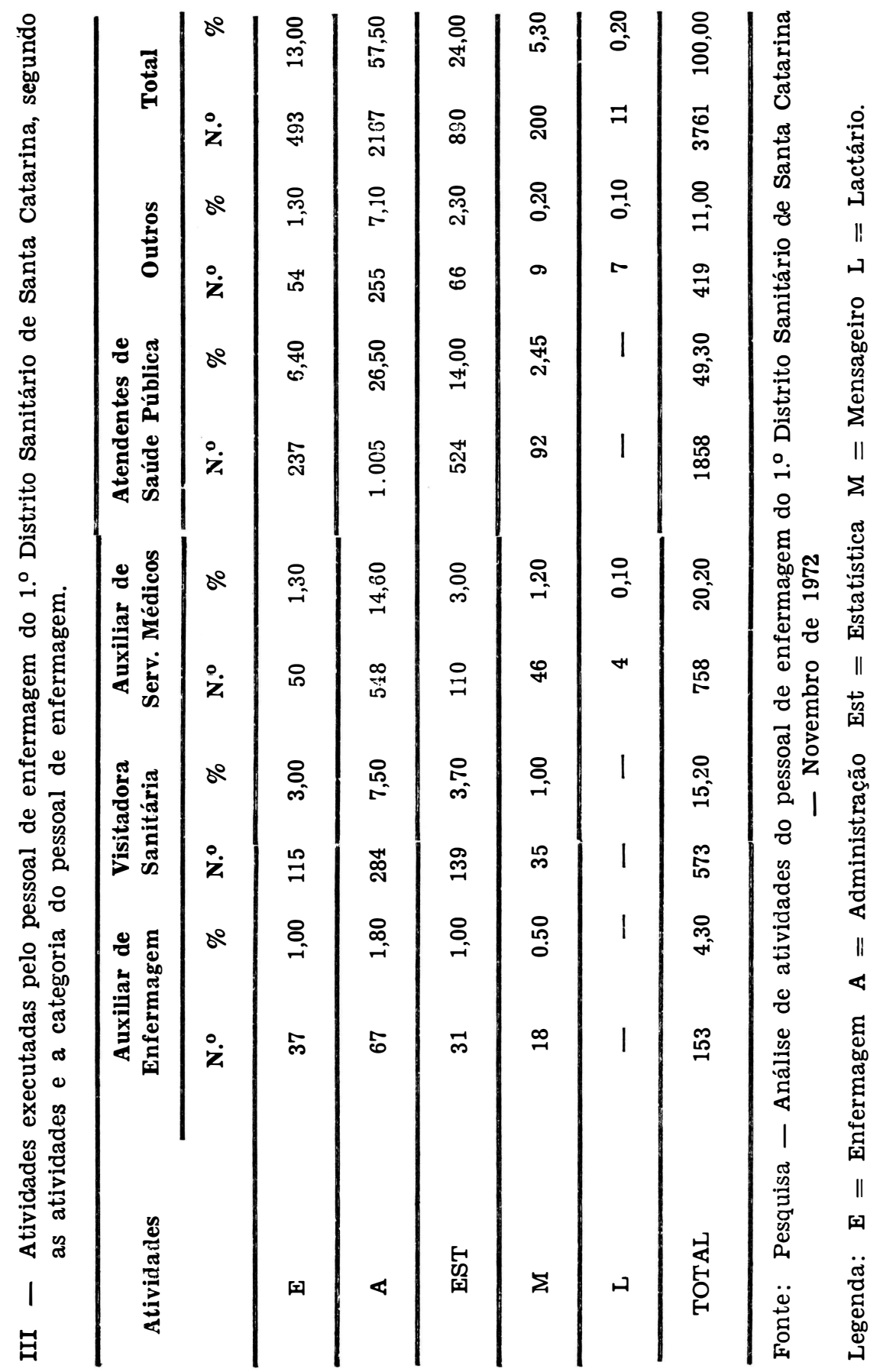


No que se referia à equipe de enfermagem tinha-se em mente que a mesma devia viver uma mesma filosofia de trabalho, crescer continuamente em termos profissionais e participar ativamente das programações do setor.

Com o objetivo de planejar a implantação do sistema determinou-se como etapas que deveriam ser desenvolvidas durante todo o processo:

3.3.1 - Definição da filosofia e objetivos da Seção de enfermagem;

3.3.2 - Definição das atividades mínimas de enfermagem;

3.3.3 - Definição das atribuições do pessoal de enfermagem, segundo preparo, categoria, função e atividades;

3.3.4 - Elaboração do manual de normas e procedimentos técnico-administrativos de enfermagem;

3.3.5 - Levantamento dos recursos materiais e financeiros para o desenvolvimento do sistema;

3.3.6 - Recrutamento, seleção e treinamento das enfermeiras;

3.3.7 - Definiição do esquema de supervisão e esquematização do processo de aperfeiçoamento das enfermeiras;

3.3.8 - Estabelecimento das linhas de coordenação com os órgãos formadores de recursos humanos e demais instituições de saúde;

3.3.9 - Definição e implantação do sistema de informações de enfermagem;

3.3.10 - Esquematização e implantação do processo de avaliação;

3.3.11 - Avaliação inicial do sistema implantado.

Para a execução destas atividades em 1973 elaborou-se uma relação apresentada a seguir, em ordem de execução.

1 - definição da filosofia e objetivos da Seção de Enfermagem;

2 - definição das atividades mínimas de enfermagem;

3 - eaaboração das atribuições da equipe de enfermagem;

4 - elaboração de manual de normas e procedimentos técnicos e administrativos de enfermagem;

5 - identificação do equipamento mínimo necessário ao Serviço de Enfermagem;

6 - determinação dos critérios para relação dos enfermeiros;

7 - estabelecimento das linhas de coordenação com órgãos formadores de recursos humanos e órgãos afins;

8 - programação do treinamento de enfermeiras;

9 - seleção e treinamento de enfermeiras; 
10 - adaptação do planejamento global de enfermagem para o nível regional com participação das enfermeiras contratadas;

11 - adaptação das enfermeiras nos CARS;

12 - definição do esquema de supervisão e esquematização do processo de atualização das enfermeiras;

13 - supervisão;

14 - planejamento e organização administrativa do Serviço de Enfermagem;

15 - avaliação do sistema de enfermagem;

16 - avaliação e reformulação das normas e rotinas de atividades de enfermagem;

17 - elaboração do programa para o ano em curso.

A definição da filosofia do S.E. foi o primeiro passo e, possivelmente um dos mais difíceis, uma vez que devia conter a nossa crença sobre a enfermagem de Saúde Pública. A ideologia devia ser bastante geral para abranger todos os aspectos, profunda para servir como diretriz, objetiva para ter aplicabilidade e não servir apenas como introdução de um manual de normas e rotinas de enfermagem.

A filosofia do Serviço de Enfermagem do DASP foi definida nos seguintes termos:

- Sua base fundamental é o respeito à dignidade humana considerando o homem integralmente nos seus aspectos biológicos, emocional e social.

- $\mathrm{O}$ indivíduo e a comunidade têm o direito de receber a atenção integral de enfermagem.

- Utilizando os conhecimentos técnico-científicos atualizados de enfermagem, participa no desenvolvimento de ações de promoção, proteção, recuperação e reabilitação da saúde individual e da comunidade, obedecendo a política de saúde estabelecida.

- E necessário aproveitar e estimular ao máximo as condições e potencialidades técnicas humanas, individuais e de equipes proporcionando um melhor preparo ao pessoal de enfermagem e mantendo um bom clima de relações interpessoais.

- A coordenação entre serviços de enfermagem da área hospitalar, órgãos formadores de recursos humanos e enfermagem de Saúde Pública é necessária para assegurar a assistência integral de enfermagem à comunidade.

- A participação do pessoal de enfermagem é essencial na equipe multiprofissional com igualdade de direitos e deveres e com respeito e confiança mútua.

- Deve, este pessoal participar na programação geral do DASP, adequando seus próprios objetivos com o dos demais membros da 
equipe, compartindo e diferenciando as funções, aceitando e proporcionando ajuda.

Os objetivos do Serviço de Enfermagem foram assim definidos: Objetivo Central:

Assegurar a atenção de enfermagem adequada e competente ao indivíduo e à comunidade, baseada no diagnóstico de enfermagem e na política de saúde estabelecida.

Objetivos Contributivos:

- Identificar as necessidades de enfermagem de indivíduos e da comunidade; Elaborar e avaliar as normas do Serviço de Enfermagem;

- Elaborar, desenvolver e avaliar as normas de atenção integral de enfermagem a indivíduos e à comunidade;

- Definir a política de pessoal do Serviço de Enfermagem;

- Elaborar, coordenar e supervisionar a implantação dos programas de enfermagem procurando a coordenação com os serviços de enfermagem das unidades hospitalares;

- Prever o orçamento para assegurar a atenção de enfermagem;

- Elaborar e avaliar programas de educação contínua para o pessoal de enfermagem;

- Participar como membro ativo da equipe multiprofissional no planejamento e desenvolvimento dos programas gerais de saúde;

A definição das atividades mínimas de enfermagem para programa Materno-Infantil foram estabelecidas em trabalho conjunto da Assessoria Técnica da Secretaria de Estado da Saúde e Serviço de Enfermagem do DASP, baseada na pesquisa sobre a utilização àos Recursos Humanos.

As atividades minimas foram assim definidas:

O controle de enfermagem à gestante compreende as seguintes atividades:

- Peso P.A. e temperatura;

- Encaminhamentos (exames laboratoriais, serviço odontológico e outros);

- Educação Sanitária;

- Controle de sinais e sintomas anormais de gravidez; viço;

- Vacinação anti-tetânica, conforme esquema adotado pelo ser-

O controle de enfermagem à criança de 0-7 anos compreende a verificação de:

- Peso

- Altura

- Temperatura

- Perímetro cefálico e toráxico 
- Vacinação conforme o esquema adotado pelo serviço

- Encaminhamentos (Serviço Odontológico e exames laboratoriais e outros)

\section{4 - AVALIAÇÃo}

Procurou-se, scb todas as formas, fazer o grupo de enfermeiras participar da posição definída e auxiliar na implantação de um esquema de trabalho que se acredita ser o caminho para a Enfermagem de Saúde Pública em Santa Catarina.

Ao final do $1 .^{\circ}$ ano fez-se a primeira avaliação que constou de:

- preenchimento pelas enfermeiras de um formulário para auto-avaliação (anexo I) ;

- entrevistas individuais e de grupo;

- análise da qualificação e quantificação das atividades executadas a nível central e regional; do DASP.

- avaliação do sistema adotado pela Seção de Enfermagem

Esta avaliação preliminar apresentou como aspectos positivos:

- Apoio integral da Secretaria da Saúde e Direção Geral do DASP à implantação do Sistema de Enfermagem;

- Aceitação da participação na ideologia definida de todas as enfermeiras de nível regional e local;

- Conscientização da equipe de enfermagem local de uma subordinação hierárquica ao Serviço de Enfermagem das Divisões Regionais;

- Integração das enfermeiras com os órgãos formadores nas atividades de ensino de Saúde Pública dos diferentes níveis;

- Conscientização da comunidade do papel da enfermeira de Saúde Pública;

- Crescimento profissional dos enfermeiros nos aspectos administrativos, técnicos, científicos e éticos;

- Cumprimento integral da programação prevista para 1973.

Foram identificados os seguintes aspectos negativos inerentes a uma estrutura em processo de mudança:

- Desarticulação entre as programações dos diferentes setores do DASP e o Setor de Enfermagem que se encontrava em fase de organização;

- A inexperiência das enfermeiras de nível central em estruturar serviços de âmbito estadual;

- Enfermeiros com habilitação em Saúde Pública apresentavam elevado grau de conhecimentos científicos, pouca habilidade 
técnica, inexperiência em atividades de ensino e de administração de serviços de enfermagem;

- Centralização excessiva das decisões de enfermagem a nível de Seção;

- O relacionamento entre a equipe de saúde a nível regional devido à existência do Sistema de Enfermagem.

\section{5 - IDENTIFICAÇÃO DOS PROBLEMAS}

Foram identificados como problemas:

- Aceitação multidisciplinar da enfermeira, pela equipe, como profissional capacitado e com direitos e poderes decisórios em assuntos técnicos que dizem respeito à Enfermagem;

- Falta de conscientização da equipe multidisciplinar para o desenvolvimento de ações integradas de Saúde;

- A deficiência de interação entre os serviços de Saúde e a comunidade;

- O número reduzido de enfermeiras habilitadas em Saúde Pública;

- A dificuldade de se obter mão de obra especializada para atuação dos CARS e Unidades Sanitárias locais do interior do Estado;

- A Administração de Pessoal vigente no DASP;

- A atenção de enfermagem à comunidade sendo prestada por Recursos Humanos sem capacitação; magem;

- Distorções de funções dentro do próprio serviço de Enfer-

- Inexistência de orçamento programa.

\section{6 - CONCLUSÕES}

Considerando que o grupo traçou uma metodologia própria de trabalho e vivenciou sua implantação e avaliação inicial, apesar do Sistema estar montado há apenas 1 ano e meio, apresenta suas primeiras conclusões:

- A metodologia usada para a organização do Serviço de Enfermagem de Saúde Pública do DASP foi válida, pois permitiu que o mesmo se afirmasse dentro da estrutura em curto espaço de tempo, caracterizando-se por sua unificação e enriquecimento progressivo da equipe de enfermagem;

- A coordenação entre os órgãos formadores de recursos humanos de enfermagem nos seus diferentes níveis e serviços de enfer- 
magem de Saúde Pública possibilita melhores condições de ensino e de atenção de enfermagem à comunidade;

- Para que o Serviço de Saúde atenda às necessidades da comunidade é necessário que seus setores participem de uma ideologia única, articulem-se entre si e desenvolvam suas potencialidades.

\section{7 - RECOMENDAÇÕES}

Aos Serviços de Saúde Pública recomendamos que:

- Aceitem o enfermeiro como profissional capacitado, com direitos e poderes decisórios em assuntos técnicos que dizem respeito à enfermagem;

- Proporcionem condições aos enfermeiros para estruturar o Serviço de Enfermagem, uma vez que para atingir o seu objetivo necessitam da contribuição de uma enfermagem bem qualificada;

- Criem oportunidade para os enfermeiros se capacitarem em. administração de serviços;

Assegurem a atenção contínua de enfermagem à comunidade, prevendo em seu orçamento recursos financeiros para execução das programações de enfermagem;

Aos Serviços de Enfermagem de Saúde Pública recomendamos que:

- Utilizem os princípios fundamentais e instrumentos da moderna administração, na organização dos seus serviços;

- Procurem identificar a metodologia mais adequada para estruturação dos seus serviços;

- Redefinam o papel da Enfermagem de Saúde Púbiica junto à comunidade e às instalações;

- Mantenham seus enfermeiros integrados numa mesma ideologia para o fortalecimento da estrutura.

Aos órgãos formadores de recursos humanos de enfermagem dos diferentes níveis recomendamos que:

- Procurem integrar-se aos Serviços de Enfermagem de Saúde Pública, visando adaptar o conteúdo da disciplina de Saúde Pública aos programas de Saúde existentes;

- Intensifiquem as oportunidades para os alunos desenvolverem habilidades técnicas básicas;

- Participem da capacitação dos Recursos Humanos dos Serviços de Enfermagem de Saúde Pública e hospitalares.

Aos órgãos formadores de recursos humanos de enfermagem de nível superior recomendamos que: 
- Ofereçam aos alunos condições de desenvolver com mais freqüência atividades relacionadas com ensino e administração de serviços de enfermagem;

- Participem junto à enfermagem hospitalar e de Saúde Pública nos seus programas de capacitação de Recursos Humanos de Enfermagem.

Aos Serviços de Enfermagem Hospitalar recomendamos que:

- Articulem-se com os Serviços de Enfermagem de Saúde Pública, visando assegurar a continuidade da atenção de enfermagem junto ao indivíduo;

- Promovam encontros com os profissionais de enfermagem de Saúde Pública para troca de experiências objetivando assegurar a atenção integral de Enfermagem.

\section{ANEXO I}

DEPARTAMENTO AUTÔNOMO DE SAÚDE PÚBLICA

DIVISÃO TÉCNICA

SEÇÃO DE ENFERMAGEM

FICHA DE AUTO - AVALIAÇÃO

I - APARENCIA PESSOAL

1. Postura:

- de pé

- no trabalho

- no andar

- no sentar

2. Uniforme:

- completo

- apresentação

II - EXECUÇÃo NO TRABALHO

1. Execução das técnicas

- segurança ao paciente

- conforto ao paciente

- ex:íidão

- habilidade (destreza, inteligência, aptidão por alguma coisa)

- rapidez 
- ordem e limpeza do material

- bom acabamento do trabalho

2. Anotações:

- completa

- concisa (exata e resumida)

- coerente

- digna de nota

- legível

- Linguagem correta

- Verdadeira

3. Observações nas necessidades do ambiente do trabalho e zelo pelo material:

- suprimento do material de consumo e medicamentos

- comunicação do material e instalações danificadas

- economia do material

- conservação do material

- controle do material

4. Freqüência:

- excelente - nenhuma falta

- bom - 1 atestado médico cada 3 meses)

- regular - 2 atestados médicos (cada 3 meses)

- insuficiente - 3 ou mais atestados médicos e faltas não justificadas.

5. Pontualidade:

- excelente -1 atraso até $15^{\prime}$ (cada 3 meses)

- bom -2 atrasos até 15 '

- regular -2 atrasos mais de 15 minutos

- insatisfatório - 3ou 4 atrasos de até 15 ' e atrasos não justificados classificam-se em insatisfatórios.

6. Observância das normas e rotinas do serviço:

- excelente - observa com exatidão as normas e rotinas de serviço

- bom - observa, com raras falhas, as normas e rotinas do serviço.

- regular - observa-se com freqüência, falhas as normas e rotinas do serviço

- insuficiente - observa, raramente, as normas e rotinas do serviço 


\section{III - PERSONALIDADE}

\section{Iniciativa:}

- E capacidade de pensar e agir com senso comum na falta de normas e processos de trabalho previamente determinados, assim como a de apresentar sugestões ou idéias que tendam ao aperfeiçoamento do serviço

- Excelente - excepcional iniciativa

- bom - demonstra iniciativa com freqüência

- regular - demonstra iniciativa ocasionalmente

- insatisfatória - não possui iniciativa

2. Colaboração:

- E a faculdade de oferecer a outrem ajuda para o cumprimento de um dever comum

- Excelente - é muito prestativo. Age com perfeita harmonia com o grupo de trabalho

- bom - coopera normalmente com pessoas com quem trabalha

- Regular - pouco coopera com os outros - E individualista. Por vezes provoca alterações no serviço

- Insatisfatória - não concorda e não coopera com ninguém

3. Adaptabilidade:

- E capacidade de ajustar-se ao meio, ao ambiente, ao grupo de trabalho e as atribuições que executa

- Excelente - Ajusta-se facilmente às situações novas

- Bom - normalmente se ajusta

- Regular - ocasionalmente apresenta dificuldades de ajustamento

- Insatisfatório - raramente se ajusta

4. Responsabilidade:

- E a capacidade de assumir e cumprir as obrigações que lhe são confiadas

- Excelente - dedica-se ao trabalho até sua satisfatória execução. Necessita de mínima supervisão.

- Bom - frequentemente aceita e executa as obrigações que lhe são confiadas. Necessita de alguma supervisão

- Regular - evita assumir atribuições fora da rotina. Necessita de estímulo e supervisão frequentemente no cumprimento de suas obrigações. 
- Insatisfatório - descarrega a responsabilidade nos outros. Necessita de supervisão constante na execução de suas tarefas.

\section{Discernimento:}

- É a capacidade para avaliar e determinar a prioridade dos problemas surgidos no trabalho.

- Excelente - resolve com eficiência, rapidez e segurança os problemas surgidos no trabalho

- Bom - Geralmente encontra soluções acertadas para seus problemas no trabalho (rotineiros ou não)

- Regular - Geralmente seguro em problemas rotineiros. Fora disso é vacilante.

- Insatisfatório - Preocupa-se com ninharias, não resolve os problemas no seu trabalho

6. Interesse pelo trabalho:

- E o interesse demonstrado no aperfeiçoamento de seus métodos de trabalho.

- Excelente - perfeito conhecimento do serviço. Interessado em adquirir novos conhecimentos para o atendimentos das necessidades futuras

- Bom - conhecimentos teóricos e práticos normais bem informado sobre as principais atividades do seu setor.. Interessa-se ocasionalmente pela aquisição de novos conhecimentos

- Regular - conhece satisfatoriamente seu trabalho, mas limita-se aos conhecimentos e experiências adquiridas. Não se interessa em progredir.

- Insatisfatório - desconhece os princípios básicos do trabalho. E indiferente ao que se passa em torno de si.

7. Espirito de observação:

- E a capacidade para observar através da percepção intelectual e sensorial e com auxílio de instrumentos (termometros, aparelho de TA, estetoscópio, etc...) as necessidades e as modificações apresentadas pelo paciente ou pela situação

- excelente - sempre alerta às necessidades e mudanças das condições do paciente, providenciando o atendimento imediato de suas necessidades

- Bom - observa as necessidades do paciente ou da situação, porém, seu atendimento imediato é falho 
- Regular - observa sempre as necessidades e modificações das condições do paciente, porém não providencia seu atendimento imediato

- Insatisfatório - raramente observa as modificações e necessidades do paciente e não providencia o seu atendimento imediato

8. Relações Humanas:

- E capacidade de estabelecer um convívio harmonico e compreensivo com:

- pacientes

- familiares

- visitantes

- superiores

- médicos

- colegas

- outros

9. Estabilidade Emocional

- E capacidade de manter um perfeito controle emocional

- Excelente - perfeita atitude de equilíbrio em qualquer situação. Capaz de reajustamento às pessoas e circunstâncias

- Bom - mantém controle emocional na maioria das situações. Atencioso e cortez

- Regular - geralmente controlado nas atitudes. Raramente impulsivo

- Insatisfatório - propenso a descontrolar-se em momentos críticos. Tem ímpetos violentos. Não admite censuras.

10. Interesse pelo progresso cultural e científico:

- E $\mathrm{E}$ interesse demonstrado por ampliar seus conhecimentos teóricos e práticos

- assistência à reuniões de trabalho;

- assistência às palestras;

- assistência aos cursos;

- assistência aos filmes científicos;

- assistência às aulas promovidas pela coordenação de educação em serviço;

- aceitação de críticas construtivas, reconhecimento da necessidade de supervisão e o aproveitamento adequado dos ensinamentos informais;

- uso frequente do prontuário para melhor conhecimento do paciente. 
IV - 11. ÉTICA PROFISSIONAL

- dever de todo o pessoal de enfermagem cumprir as determinações éticas de sua profissão consubstanciados principalmente, nos seguintes aspectos:

- guardar segredo - entre colegas, doentes, amigos, familiares, etc. sobre os fatos de que tenha conhecimento por ter visto, ouvido ou deduzido na sua atividade profissional;

- respeitar as crenças religiosas e a liberdade de consciência de seus pacientes proporcionando-lhes assistência espiritual;

- procurar manter confiança que o doente e seus familiares depositam no médico e nos outros membros da equipe de saúde;

- a imperícia de alguns membros da equipe de saúde só deve ser comunicada, em último recurso, à autoridade competente;

- não aceitar retribuições pelos seus serviços além de vencimentos que lhe são devidos pelo contrato de trabalho;

- cuidar com dedicação e solicitude de todos os pacientes independentemente de sua raça, nacionalidade, partido político, classe social ou religiosa.

\section{BIBLIOGRAFIA}

1 - ELSEN, I, MEDEIROS, M.M.B. - Manual de Normas e Procedimentos Técnico-Administrativos da Enfermagem do DASP. Florianópolis, 1973.

2 - LOPEZ, Joana, P. - A Enfermeira de Saúde Pública. Contribuição ao estudo de suas funções.

Tese de Doutoramento - Departamento de Prática de Saúde Pública, São Paulo, 1971.

3 - OPS/OMS - Plano Decenal de Saúde para as Américas, - Santiago, Chile, 1972.

4 - OPS/OMS - Sistema de Salud - 1972.

5 - OPS/OMS - Administracion de Servicios de Enfermeiria - Fundamentos de Administracion. Tomo I - 1971.

6 - OPS/OMS - Administracion de Servicios de Enfermeria. Planejamento del cuidado del paciente. Tomo II - 1971.

7 - OPS/OMS - Administracion de Servicios de Enfermeria. Supervision. Tomo III - 1971.

8 - PAN AMERICAN HEALTH ORGANIZATION - Administracion de Servicios de Enfermeria. Educacion en Servicio. Tomo IV, 1968.

9 - RIBEIRO, Circe M. - Organização de Serviço de Enfermagem. Rev. Brasileira de Enfermagem 26 (3) 21. abril-jun. de 1973.

10 - VERHONICK, P.H.J. - Métodos de Estudos Descritivos en Enfermeria. OPS/OMS, Genebra, 1971. 